The

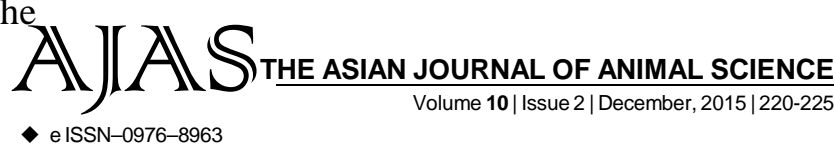

DOI : 10.15740/HAS/TAJAS/10.2/220-225 Visit us | www.researchjournal.co.in $\mathrm{S}$

A REVIEW

\title{
Nutritional role of milk fatty acids to human health and its functional and biochemical properties
}

SAROJ AND SUBHA GANGULY

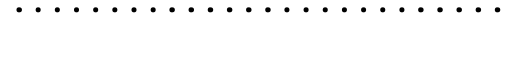

Author for Corresponding -

\section{SUBHA GANGULY}

Department of Veterinary

Microbiology, Arawali Veterinary

College, Bajor,

SIKAR (RAJASTHAN) INDIA

Email: ganguly38@gmail.com

See end of the article for

Coopted authors'

\begin{abstract}
Ruminant milk fat is an important component of the human diet, particularly bovine milk fat which makes the 75 per cent of total consumption of fat from ruminant animals. All ruminant milk contains lipids but the concentration varies according to species from 2 to 8 per cent (Belitz and Grosh, 1999). The principle function of dietary lipid is to serve as a source of energy for the neonate and the fat content in milk largely reflect the energy requirements of the species, e.g. land animals indigenous to cold environment and marine mammals secrete high levels of lipids in their milk, apart from being main source of energy, milk lipids serve as a source of essential fatty acids (i.e. fatty acids which cannot be synthesized by higher animals, especially linoleic acid (C 18:2) and fat soluble vitamin (A, D, E, K); also for the flavour and rheological properties of dairy products and foods in which they are used.
\end{abstract}

KEY WORDS...... Fatty acid, Human health, Milk, Nutrition

HOW TO CITE THIS ARTICLE - Saroj, Tyagi, A.K. and Ganguly, Subha (2015). Nutritional role of milk fatty acids to human health and its functional and biochemical properties. Asian J. Animal Sci., 10(2): 220-225.

ARTICLE CHRONICLE - Received : 02.09.2015; Accepted : 27.11.2015 